Dept. of Anatomy and Histology,

Fac. of Vet. Med., Assiut University, Assiut 71526, Egypt.

\title{
IMMUNOMORPHOLOGICAL STUDY OF ULTIMOBRANCHIAL BODY REMNANTS IN THE THYROID GLAND OF BUFFALO (BOS BUBALIS) \\ (With 9 Figures)
}

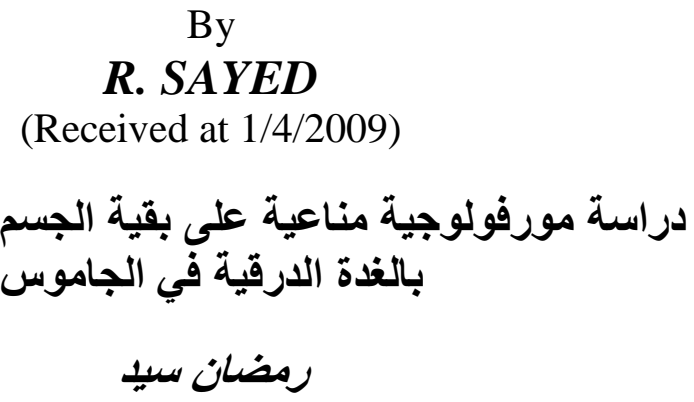

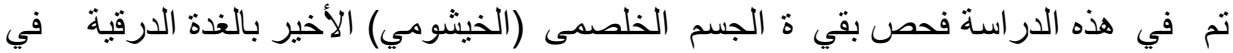

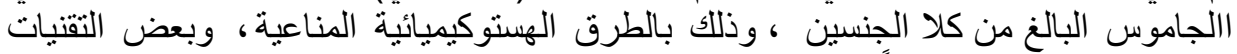

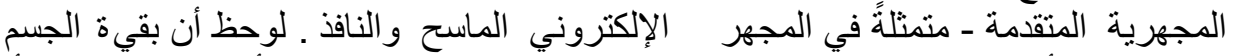

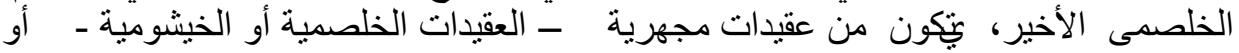

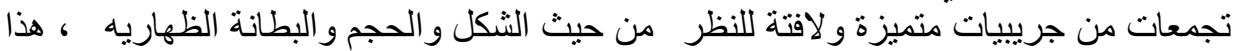

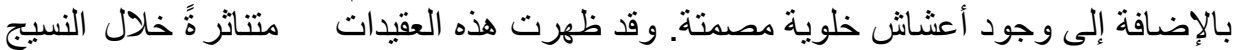

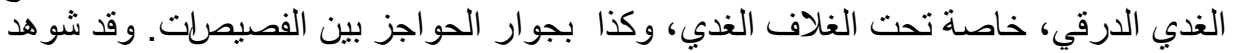

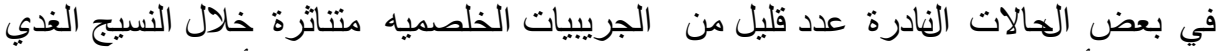

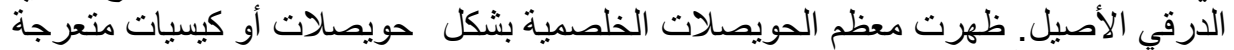

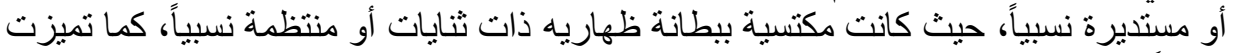

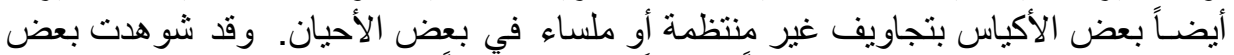

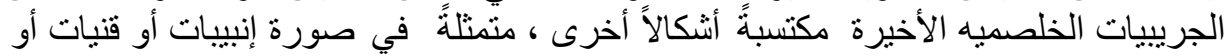

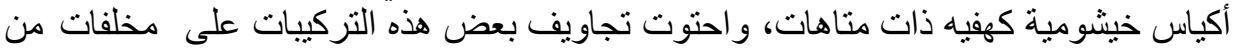

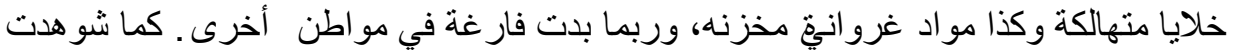

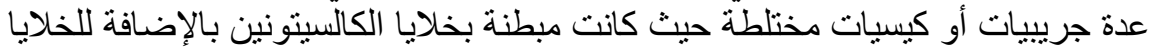

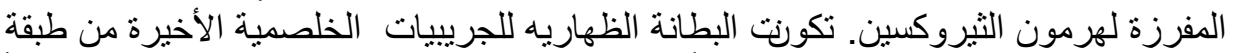

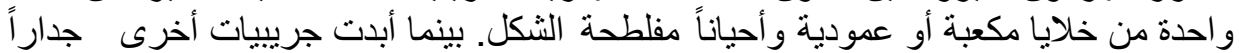

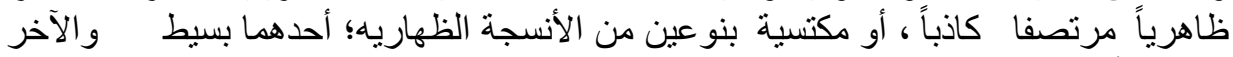

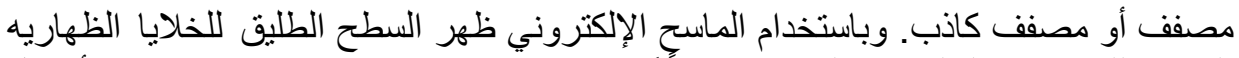

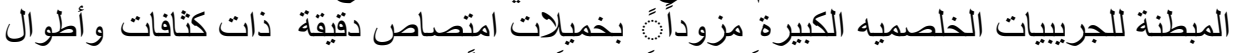

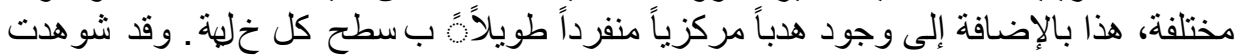

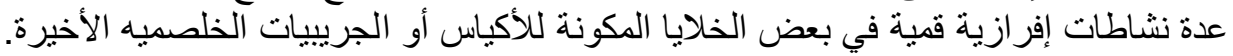

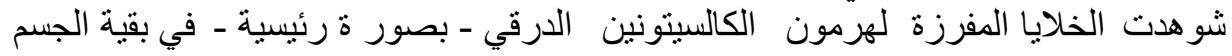




\section{الخلصمى الأخير. وقد تميزت هذه الخلايا بوجود حبيبات إفرازية مغلفة (150-200 نانوميتر )

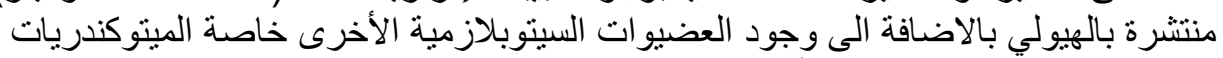 و الثبكة الاندوبلازمية الخشنة وأجسام جولجى.}

\section{SUMMARY}

The remnants of ultimobranchial body (UBB) in the thyroid gland of adult buffalo were studied. This remnant occupied a peripheral location beneath the capsule, as well as being embedded mostly in the vascular connective tissue of the thyroid. It demonstrated as microscopic nodules (ultimobranchial nodules, UB nodules), in the vicinity of thyroid capsule, septa or frequently embedded within the thyroid tissue proper. The UB nodules were consisted of various aggregations of striking follicles (ultimobranchial follicles, UBFs), exhibiting unusual shape and size and sometimes exhibited unusual lining epithelium. The UBFs had cystic-, elongated-, tubular-, duct- or labyrinth-like formations of various sizes with irregular outline and more or less folded lumen. This lumen might contain debris of disintegrating cells and/or colloid. Apart from the aggregated UB structures, occasional solitary UBFs or other related derivatives were rarely distributed within the thyroid tissue proper. The UBFs were lined with a single layer of cubical, columnar, flattened or sometimes pseudostratified epithelial formations. Solid cell nests (SCNs), as well as some cystic follicles exhibiting both simple and stratified epithelial variety were also demonstrated. In addition, mixed UB follicles that lined with both simple and stratified epithelium were also revealed. Thyrocalcitonin cells (C-cells), with various cytoplasmic intensities of immunoreactive products against anti-calcitonin human immune serum, were predominantly localized in the wall of UBFs. These cells distributed singly or in groups between the component cellular elements lining of UB structures. They characterized by the presence of fine electron dense membrane-bound granules $(150-200 \mathrm{~nm})$ scattered in the cytoplasm together with several mitochondria, small profiles of rough endoplasmic reticulum, as well as few small-flattened cisternae of Golgi apparatus. Scanning electron microscopy revealed that the surface of UB follicular cells was almost flat and polyhedral or hexagonal in shape. Other follicles possessed some cells with dome shaped apical surface demarcated by a shallow intercellular depression. The luminal surface of follicular cell lining was studded with pleomorphic microvilli which were numerous at the intercellular borders. Interestingly, most of UB follicular cells were provided with single cilium, projecting over the cell surface. Notably, some UBFs presented various stages of apocrine activities. 
Abbreviations used in this study: APUD cells, amine precursor uptake and decarboxylation cells; C-cells, Calcitonin cells; CCN(s), cystic cell nest(s); SCN(s), Solid cell nest(s); UB, ultimobranchial; UBB, ultimobranchial body; $\operatorname{UBF}(\mathrm{s})$, ultimobranchial follicle(s); UBBR(s), ultimobranchial body remnant(s).

Key words: Ultimobranchial body - Immunocytochemistry - Thyrocalcitonin cells - Scanning electron microscope

\section{INTRODUCTION}

The thyroid gland is derived mainly from a central anlage composed of proliferating endodermally derived epithelium of the pharyngeal floor, giving rise to the thyroglossal duct, the isthmus, and the major portions of the lateral lobes (Sadler, 1990). In addition, there is a lateral anlage, the ultimobranchial body, that arises in the fifth pharyngeal pouch, which in mammals is considered to be part of the fourth (Sugiyama, 1971). The UBB is composed of cells and mesenchyme of neural crest origin. Such UBB migrates caudally and fuses with the lateral lobes of the thyroid gland during embryonic life (Sugiyama, 1971; Sadler, 1990). In mammals the UBB is completely incorporated into the thyroid gland. However, in domestic fowl the UBB remains distinct from the thyroid gland. The contribution of UBB to the mammalian thyroid is important because this structure has been cited as the source of calcitonin-producing cells (C-cells) (Pearse and Polak, 1971; LeDourain et al., 1974; Polak et al., 1974). Other investigations of the thyroid gland share the view that the UBB or its remnants contribute to the development of calcitonin cells and thyroglobulin producing cells, as well as the development of some thyroid tumors (Kameda and Ikeda, 1980; Ljungberg and Nilsson 1985; Harach, 1988), including the branchial-like cysts in the neck organs, especially in the thyroid gland (Delabie et al., 1991; Apel et al., 1994; Park et al., 2004).

The previous investigations of ultimobranchial body remnants (UBBRs) in the thyroid have shown that these structures display 3 main morphological types: (1) solid, (2) cystic clusters, and (3) mixed follicles made of follicular epithelium continued with solid cell nests (Harach 1988, 1991; Mizukami et al., 1994; Kameda, 1995; Sayed et al., 2005a, b). These structures are considered to be normal components of the thyroid gland and of ultimobranchial origin (Harach, 1988; Martin et al., 2000; Sayed et al., 2005a, b). 
Several investigations on the structure of ultimobranchial rests have been performed in chickens (Kameda et al., 1993), and mammals such as dogs (Kameda and Ikeda, 1980; Kameda, 1995), bulls (Ljungberg and Nilsson, 1985), rats (Calvert, 1972), mice (Wetzel and Wollman, 1969), donkeys (Sayed et al., 2005b) and human (Kakudo et al., 1977; Harach, 1991; Martin et al., 2000; Michal et al., 2006). To our knowledge, little information is available concerning the presence, as well as the morphological and immunocytochemical aspects of UB derivatives in the thyroid gland of buffalo (Bos bubalis) (Roy and Yadava, 1975; Sayed et al., 2005a). In addition, the immunocytochemical and ultrastructural characteristics of C-cell complexes in the thyroid of buffalo are poorly documented. Therefore, the present investigation is undertaken to traces the occurrence, as well as the immunomorphological and ultrastructural features of UBBRs in the thyroid gland of buffalo. The obtained results would lead for further information that has especial importance when establishing a correlation, with a similar mammalian species which live an adverse climatic condition.

\section{MATERIALS and METHODS}

Thyroid glands from 7 adult buffalo of both sexes, aging from 3 to 12 years were freshly removed after slaughtering in an Assiut slaughterhouse. One thyroid lobe from each animal was cut transversely at 2-4 mm intervals, fixed in a solution formed of $4 \%$ paraformaldehyde in $0.1 \mathrm{M}$ phosphate buffer $(\mathrm{pH}$ 7.3). After fixation, specimens were dehydrated, cleared, embedded in paraffin and cut into transverse total serial sections of 4-5 $\mu$ m thick. Serial sections representing the whole thyroid gland were stained with hematoxylin-eosin for general purposes and topographical localization of ultimobranchial tissue in the thyroid gland.

For immunological and immunomorphological examination of calcitonin containing cells or tissues, some serial sections were immunoreacted with a human synthetic calcitonin antibody raised against a rabbit (Lab Vision Corporation, CA, USA). Briefly, sections were immersed for $30 \mathrm{~min}$ in $0.3 \% \mathrm{H}_{2} \mathrm{O}_{2}$-PBS (phosphate- buffered saline) and incubated in $2 \%$ normal goat serum for $60 \mathrm{~min}$ and then incubated with rabbit antiserum against human calcitonin overnight at $4{ }^{\circ} \mathrm{C}$. The sections were next incubated for $30 \mathrm{~min}$ at room temperature with biotinylated goat antibody against rabbit IgG (1: 200; Vector Lab). After 3 washes in PBS, they were incubated for $30 \mathrm{~min}$ at room temperature 
with ABC (avidin biotin peroxidase complex) (Vector Lab). The reaction products were visualized by incubating the sections in $0.05 \mathrm{M}$ Tris- $\mathrm{HCl}$ buffer $(\mathrm{pH}$ 7.3) containing 3,3`-diaminobenzidine tetrahydrochloride $(20 \mathrm{mg} / 100 \mathrm{ml})$ and $0.003 \% \mathrm{H}_{2} \mathrm{O}_{2}$. All sections were counterstained with Mayer's hematoxylin. The control reaction involved the replacement of the primary antiserum with non-immune rabbit serum (1:50 dilution).

For scanning electron microscopy, small blocks of thyroid tissue were freshly obtained from the region surrounding the parathyroid IV, immersed in a formaldehyde-glutaraldehyde solution in $0.1 \mathrm{M}$ phosphate buffer ( $\mathrm{pH} 7.3$ ) as described by Karnovsky (1965) for $24 \mathrm{~h}$ at $4{ }^{\circ} \mathrm{C}$. Thereafter, the tissues were post-fixed in a $1 \% \mathrm{OsO}_{4}$ solution of $0.1 \mathrm{M}$ phosphate buffer ( $\mathrm{pH}$ 7.3) for $2-3 \mathrm{~h}$ at $4{ }^{\circ} \mathrm{C}$ and dehydrated in a series of graded ethanol. After critical point drying and ion sputter coating with gold, specimens were examined in a JEOL (JSM-5400LV) or Hitachi (HS-2300) scanning electron microscope at $25 \mathrm{Kv}$.

For transmission electron microscopy, after osmication in a $1 \%$ $\mathrm{OsO}_{4}$ solution at $4{ }^{\circ} \mathrm{C}$, small blocks from the ultimobranchial tissue $\left(1 \mathrm{~mm}^{3}\right.$ thick) were dehydrated and embedded in epoxy resin. Semithin sections were cut, stained with toluidine blue and examined with a light microscope. Ultrathin sections were also obtained, stained with uranyl acetate and lead citrate, and then examined by transmission electron microscope (JEOL 100CXII EM).

\section{RESULTS}

\section{Immunomorphological findings:}

In the present investigation, the thyroid gland of adult buffalo of both sexes, revealed the existence of various microscopic nodules, consisting of several aggregation of follicles frequently associated with secondary derivatives which formed of cellular clusters the so-called solid cell nests and/or cellular streaks, as well as growing follicles at different stages of folliculogenesis. This structure postulated as the ultimobranchial body remnants, exhibiting a prominent location around the parathyroid, usually under the thyroid capsule, as well as along the connective tissue septa (Figs. 1A). In addition, small to large UBFs, singly or in groups, were occasionally demonstrated within the thyroid parenchyma proper. Interestingly, the cellular components of the UBBRs including the UBFs and associated secondary derivatives (growing follicles, and cystic or solid cell nests) showed various immunoreactivities against anti-calcitonin rabbit immune serum (Figs. 1-4). 
The ultimobranchial follicles of present investigation showed unusual or striking features including: the follicular form, size, luminal shape and content, in addition to the morphological or immunocytochemical characteristics of follicular epithelium for calcitonin immunostaining (Figs. 1-3). Cyst- like follicles possessing regular outlines and different sizes were frequently observed in the UB tissue that partially or sometimes completely disseminated within thyroid tissue proper (Fig. 1). These follicles were surrounded by a basement membrane and a layer of highly vascular connective tissue. They lined by a single layer of follicular epithelium which varied from simple squamous to cubodial formations that containing flattened to roundish central nuclei (Fig.1 A, B). Their lumens were empty or filled with colloid-like substances. Calcitonin immunostaining revealed few to numerous immunoreactive cells, distributing singly or in groups, within the epithelial lining of these follicles. The calcitonin immunopositive cells appeared with various labeling intensity of their cytoplasmic products. The luminal contents of these structures showed negative reaction for calcitonin staining (Fig.1 A). Apart from the immunopositive cyst-like follicles, occasional cystic follicles were entirely negative for calcitonin immunostaining (Fig. 1A).

Apart from the regular cystic follicles, occasional cystic UBFs that showing an irregular outline or has labyrinth-like structure were also revealed (Fig. 1A, B). These follicles were large in size, presented more or less irregular outline and corrugated lumen bounded with a single layer of folded epithelium. These labyrinth-like follicles of ultimobranchial tissue were lined by low to high cuboidal formations containing spherical central nuclei with diffused chromatin material (Fig. 2 A, B). At some follicular positions, the lining epithelium was stratified cuboidal to squamoid in its appearance (Fig. 3). In addition, the labyrinth-like follicles showed several outpocketings from their epithelial walls giving the appearance of evaginated formation for such follicles (Fig. 1B) or showed peripheral out pouching indicating the development of new follicles from the follicular wall at this location (Fig.2A). In addition, a few small separated secondary follicles were also seen in association with the follicular wall of some cystic follicles (Figs.1 A, B). Furthermore, this type of UBFs was frequently associated with cellular streaks or masses (SCNs) of proliferated basophilic epithelial cells. The cellular components of these structures were elongated, ovoid or polygonal-shaped and contained flattened to roundish central nucleus (Figs. 1A, B and 2A). Immunostaining with calcitonin antiserum 
revealed large population of immunoreactive cells that were widely distributed throughout the UB follicular epithelium and/or associating secondary derivatives with more positive reaction observed at the apical cytoplasm of the follicular epithelium (Fig.1B). Some follicular cells exhibited immunopositive apical cytoplasmic blebs (aposomes) at various stages of apocrine activity (Fig. 2A, B). Notably, the calcitonin immunoreactive cells appeared singly or in groups and showed various labeling intensities and distributions of their cytoplasmic products; some follicular cells were intensely stained, while others were faint or entirely immunonegative for calcitonin staining (Fig. 4). The follicular lumens were free of contents or occasionally contained a colloid- like substance but were entirely immunonegative for calcitonin staining (Figs. 1-4).

Cystic cell nests (CCNs), another form of UBFs associating with SCNs, were also demonstrated in the present study (Fig. 3). This type of UBFs consisted of cystic wall predominantly lined by one layer of cuboidal to flat cells, but also containing portion(s) that formed of stratified epithelial formations belonging to the squamoid or cubical variety (Fig. 3). These structures were frequently associated with clusters of proliferated cellular streaks or masses of polygonal cells containing round to oval nuclei (Fig. 3). Positive calcitonin immunoreaction was demonstrated in the follicular epithelial lining of the CCNs which appeared with various intensities, however, their associated cellular masses (SCNs) appeared immunonegative for calcitonin staining except for the superficial cell layer bordering the lumen (Fig. 3).

Tubule or duct-like follicles of small to large size which exhibiting wide to narrow branched lumen were also observed in the vascular connective tissue septa of UB tissue within the thyroid gland (Fig. 1). In addition, cellular masses were also revealed in association with these structures. The lining epithelium of these follicles varied from simple squamous with flattened nuclei to cubical variety with rounded nuclei; and that their lumens was free of contents or sometimes showed accumulated debris of nucleated or non-nucleated disintegrating follicular cells (Fig. 1A). Positive calcitonin immunostaining was found in the lining epithelial cells of some tubular follicles, but sporadically observed in some associating SCNs (Fig. 1A).

\section{Scanning electron microscopy findings:}

Three-dimensional observation of the ultimobranchial tissue revealed the existence of some large follicles, which exhibiting folded follicular epithelium and irregular outline (Fig. 5). Surface of the ultimobranchial follicular cells was almost hexagonal, carrying microvilli 
with various density and length (Figs. 5 and 6). These microvilli were much numerous at the cellular borders, but apparently scanty at the central part of cell surface. The surface cellular border was further demarcated by a shallow intercellular depression, which delineating adjacent cells (Fig. 6). In addition, the apical surface of ultimobranchial cells in some follicles was provided with a long single cilium projecting over the cell surface (Fig. 7). This cilium was apparently less distinct at the follicular cells exhibiting dense microvillus border. Interestingly, some ultimobranchial follicular cells showed various bleb-like apical cytoplasmic protrusions (aposomes), projecting over the cell surface (Fig. 8). The microvillus population at the free surface of such cells was almost poorly developed which appeared sparse or short in height (Fig. 8). The protruded blebs were varied in shape and size and apparently showed smooth or undulated surface. Deep to shallow eroded or circumscribed areas, of the apical cell surface of some ultimobranchial cells, were frequently demonstrated, representing the morphological signs of the various stages of apocrine activity (Fig. 8).

\section{Transmission electron microscopy findings:}

The parafollicular calcitonin cells were predominantly found in the follicular wall of UBFs or sometimes gathered into small nests within the vascular interfollicular space. Within the follicular epithelial wall they laid directly over the basal lamina which usually bordered the follicular lumen. Within the interfollicular space, the C-cells appeared oval, elongated or ellipsoid in shape and contained oval nucleus containing few electron dense chromatin substance and prominent nucleolus. However, the follicular calcitonin cells were cubical to columnar and contained roundish to oval nuclei (Fig. 9). The lowelectron dense cytoplasm was characterized by the presence of a large number of fine electron dense membrane- bound granules measuring 150-200 $\mathrm{nm}$ in diameter, which distributed throughout the cytoplasm or located near the basal or vascular pole of the cell. In addition, the cytoplasm showed few small-flattened cisternae of Golgi apparatus together with occasional membrane-bound vacuoles, several profiles of rough endoplasmic reticulum, as well as scattered mitochondria (Fig. 9).

\section{LEGENDS}


Fig. 1: Immunomorphology of one ultimobranchial nodule in the thyroid gland of adult buffalo.

A: Thyroid of adult buffalo shows sector from an ultimobranchial nodule, demonstrating various formations of immunoreactive UBFs lies near the capsule, as well as along the vascular connective tissue septa (S). Notice the UBFs appears with different shapes and sizes. C, cystic UBF; L, labyrinth-like UBF with irregular outline and folded lumen; T, tubular UBF with irregular outline and slit-like irregular lumen containing cell debris or desquamated cells; double arrowheads pointing to SCN. Immunoperoxidase method using anti-calcitonin immune serum, counter-stained with Meyer's hematoxylin. X100.

B: Closer view from Fig. A shows cystic (labyrinth-like) UBF lined with cubical to attenuated formations with various immunoreactivity in the cellular cytoplasm. L, labyrinth-like cyst joined to a tubule. Notice the outpocketings (Arrows) of the follicle, cellular streak (double arrows) and the smaller follicles in association to the UB follicular wall. Immunoperoxidase method using anti-calcitonin immune serum, counter-stained with Meyer's hematoxylin. X200.

Fig. 2: Immunomorphology of UBFs lies in the vascular interlobular septum.

A: Labyrinth- like calcitonin immunoreactive UBF (L) intercommunicated with outpouching tubular follicle (T). FCN, small UBF adjoining with solid cell mass (Asterisk). Notice, the cytoplasm of follicular cells appears with various reactivities, some cells are strongly reactive for calcitonin and the other ones are negative or faintly immunostained. Arrowheads indicate strongly immunoreactive apocrine blebs and double arrowheads indicate SCN. Immunoperoxidase method using anti-calcitonin immune serum, counter-stained with Meyer's hematoxylin. X200.

B: Closer view of Fig. A. The lining epithelium is formed of cubical to low columnar formations; the reactive cytoplasmic product of the follicular cells appears with various staining intensities. Arrowheads indicate aposomes stained intensely for calcitonin. Immunoperoxidase method using anti-calcitonin immune serum, counter-stained with Meyer's hematoxylin. X400. 
Fig. 3: Cystic cell nest (CCN) lined with cubical to attenuated cells and stratified cubical follicular epithelium. Notice some follicular cells are moderately reactive for calcitonin and the other ones are negative or faintly immunostained that shows various immunoreactive products in their apical cytoplasm. The cell cluster (Asterisk) in the wall of the cyst is immunonegative for calcitonin except for the superficial layer bordering the cystic cavity. Immunoperoxidase method using anti-calcitonin immune serum, counter-stained with Meyer's hematoxylin. X400.

Fig. 4: Closer view of the follicular epithelium of an UBF showing cubical to low columnar follicular cells. Notice the various intensities and distributions of immunoreactivitie products in the cytoplasm of follicular cells. Immunoperoxidase method using anti-calcitonin immune serum, counter-stained with Meyer's hematoxylin. X400.

Fig. 5: Scanning electron micrograph of the thyroid gland showing large ultimobranchial follicle (UBF) in the buffalo thyroid. Notice the irregular outline and folded lumen of the UBF. X50

Fig. 6: Scanning electron micrograph of the inner surface of an UBF showing microvillus follicular cells with flat polyhedral surface. Notice the microvilli are apparently condensed at the periphery or cellular border. X2000.

Fig. 7: Three dimensional scanning electron micrograph of the inner surface of an UBF showing flat polyhedral surface cells, each present's single cilium and pleomorphic microvilli. The microvilli are numerous and appear condensed at the intercellular borders. $\mathrm{X} 3.500$.

Fig. 8: Three dimensional scanning electron micrograph of the inner surface of an UBF showing various apocrine protrusions (aposomes) at the apical surface of some ultimobranchial cells (Asterisks). X1500.

Fig. 9: Transmission electron micrograph showing a calcitonin cell lies between the follicular cells of mixed UBF. The nucleus of calcitonin cell $(\mathrm{N})$ is oval and the cell lies at the basement membrane (Arrowhead) with its apical surface reaching the follicular lumen (L). FC, follicular cell. Notice the fine electron dense secretory granules scattered throughout the cytoplasm. M, mitochondria; $\mathrm{R}$, cisternae of rough endoplasmic reticulum. X6700. 
Assiut Vet. Med. J. Vol. 55 No. 122 July 2009
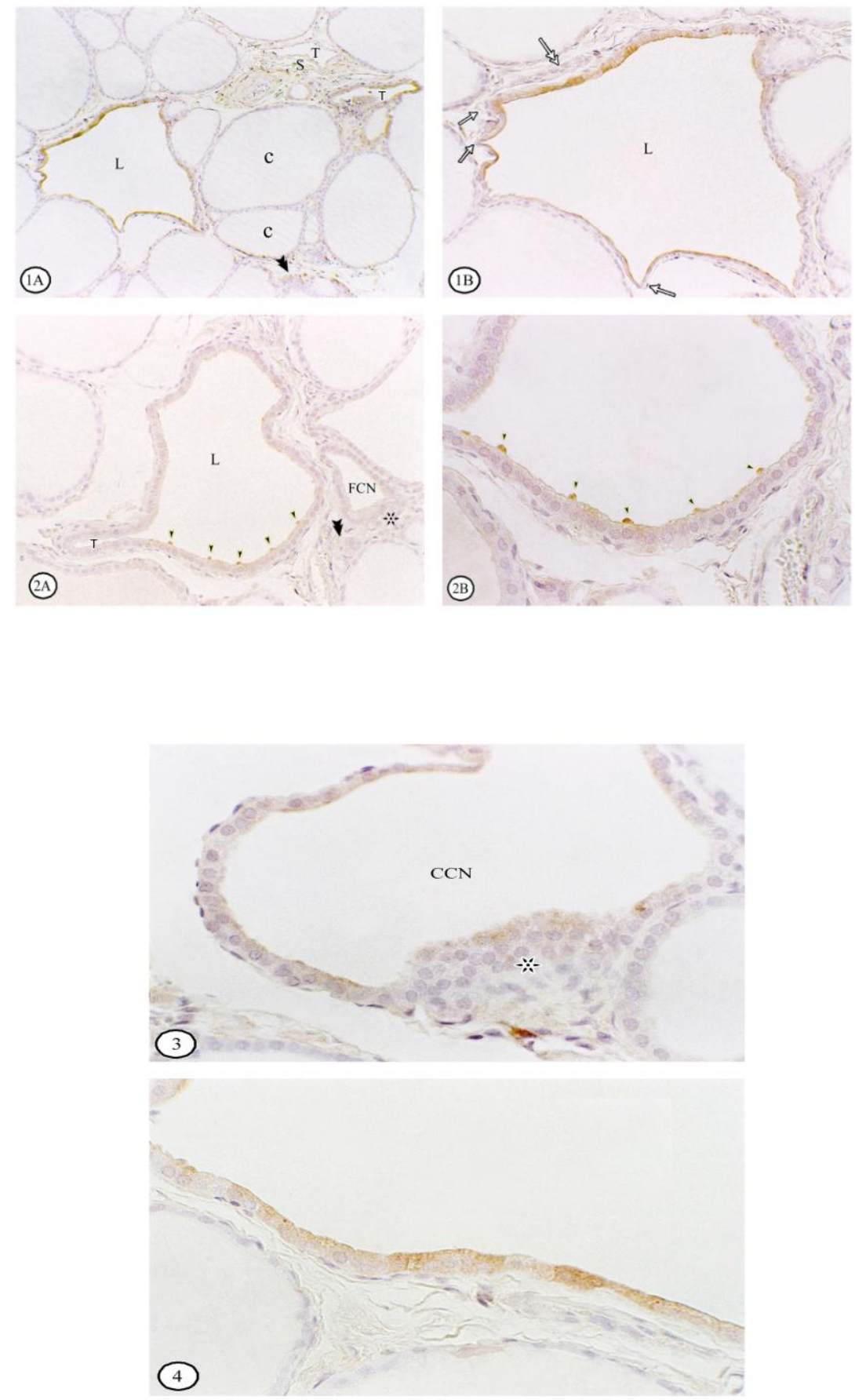

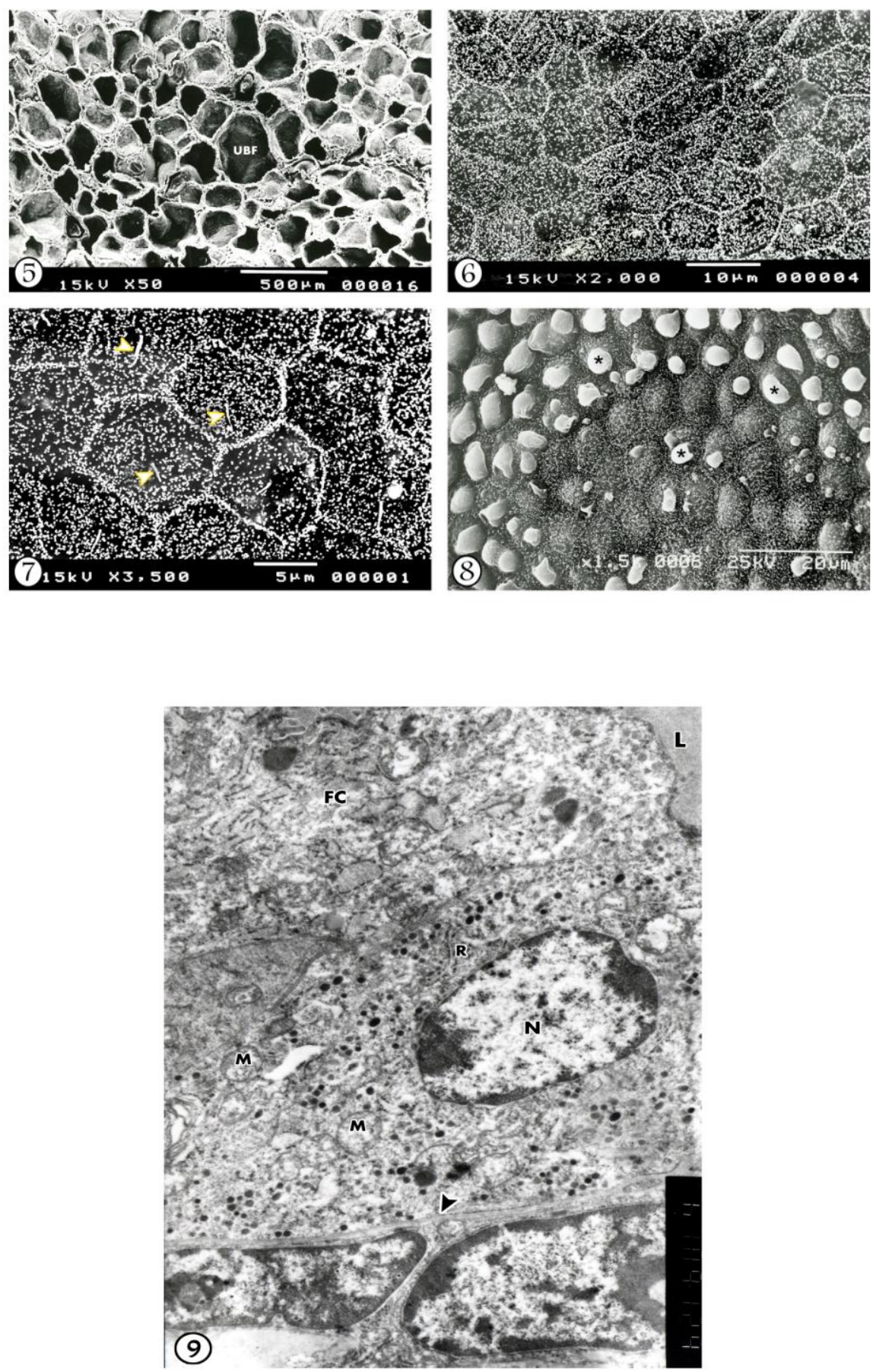


\section{DISCUSSION}

\section{General considerations}

The ultimobranchial body is an endocrine gland originating from the fourth pharyngeal pouch which fuses with the thyroid diverticulum and then partially or completely dispersed into the parenchyma, giving rise to the so-called UBBRs or solid cell nests including calcitoninproducing C-cells (Roediger et al., 1977; Kameda et al., 2007). The UBBRs contributes to the embryological development of the thyroid (Apel et al., 1994), and are believed to be involved in the development of C-cells (Patey et al., 1996). In mammals, SCNs including mixed thyroid follicles and associated C-cells represent remnants of the UBB and considered as normal components of the thyroid gland (Pianzola et al., 1992; Kameda, 1995; Patey et al., 1996; Sayed et al., 2005a, b). The UBBRs or parafollicular C-cell system of present study included UBFs of various sizes and shapes, cysts, tubules, and mixed thyroid follicles, as well as solid and cystic cell nests that formed by immature cells which were functionally and structurally undifferentiated. In addition, the UBBRs showed thyroglobulin producing cells as well as calcitonin immunopositive cells. These observations are in line with MéridaVelasco et al. (1989).

\section{The C-cell complexes are normal components of thyroid gland of mammals}

In the present study, the adult thyroid gland in buffalo demonstrated various microscopic nodules consisting of several aggregations of follicles of various sizes and shape, which frequently associated with secondary derivatives, formed of cellular masses the socalled solid cell nests and including cellular streaks, as well as growing follicles at different stages of differentiation. Furthermore, such UB nodules contained regular cystic or labyrinth-like follicles, with folded epithelium and irregular outline which lined mostly with calcitonin immunopositive cellular population together with unstained or immunonegative follicular cells. In addition, small to large UBFs, singly or in groups, were occasionally demonstrated within the thyroid parenchyma proper of present study. This structure, the so-called SCNs or C-cell complexes, previously postulated as the remnants of the embryonic UBB (Kameda, 1995), exhibiting a prominent location near the parathyroid IV, usually under the thyroid capsule, as well as along the connective tissue septa. 
The ultimobranchial C-cell complexes in human thyroid are irregular structures of about $1 \mathrm{~mm}$ in diameter, usually found in the middle third of the thyroid lateral lobes (Harach, 1985). These structures are closely related to certain cells of UBB vestiges which may be not of neuroectodermal origin but of endodermal origin (Ozaki et al., 1991). In mammalian species, including the buffalo (present study), the C-cells were partially or completely disseminated among the follicles of the thyroid gland; but they occasionally formed fairly large cellular clusters around or near the parathyroid IV (Kameda, 1977, 1982, 1995; Kameda and Ikeda, 1980), which were regarded as the remnant of the embryonic UBB (present study). Parafollicular cells occasionally formed narrow to large colloid-containing follicles. The follicular cells in the parafollicular cell complex elaborate 19S thyroglobulin and stored it as colloid droplets in the follicular lumen (Kameda, 1977). The secretory products showing colloid-like, flocculent, or granular features are intensely stained with the anti-19S thyroglobulin and anti-C-thyroglobulin antisera (Kameda, 1977).

\section{Immunomorphological features and cellular components of UBBRs in mammalian thyroid gland}

The present study of UBBRs showed occasional UBFs exhibiting tubule or duct- like formation, with wide irregular outline and highly folded lumen. The lumen was irregular and free of contents or sometimes showed accumulated debris of nucleated or non-nucleated disintegrating follicular cells within their lumens. However, some UBFs of present investigation were extremely large, exhibited oval to roundish cyst-like formation and showed more or less folded epithelial membrane. The luminal cavity was mostly less regular and frequently contained calcitonin immunonegative colloid-like materials. Other UBFs of present study extended into various peripheral out pouching and sometimes continued with those of some adjacent follicles. The epithelial membrane of these follicles was highly folded and formed of single layer of cubical cells containing roundish nucleus. This type of UBFs was frequently associated with streaks or masses of proliferated epithelial cells and/or small secondary follicles at different stages of follicular development.

The ultimobranchial tissue in the thyroid gland of mammals including buffalo (present study) has the shape of irregular cysts (Zelander and Kirkeby, 1977; Sayed et al., 2005a, b) or labyrinth-like cysts (Michal et al., 2006), and/or present in the form of ducts, follicles and/or mixed follicles, which are in continuity within the thyroid parenchyma (Calvert, 1975; Sayed et al., 2005a, b). The SCNs of present 
study communicated with the UB structures of which the former represented the most distal outpouchings or outgrowths of the latter (Michal et al., 2006). In goats, the UB follicles varied greatly in shape which were narrow or wide tubular, epithelial pear like, long follicle with colloid, bilobed, evaginated, sheet of stratified squamous cells attached to follicle, and a group of follicles (Roy et al., 1978). The latter three forms of follicles were due to the branching of main stem UB follicle, present at different levels (Roy et al., 1978). The UBBRs or parafollicular C-cell system in humans included UBFs, cysts and tubules, as well as solid nests formed by basophilic immature cells which were functionally and structurally undifferentiated (Mérida-Velasco et al., 1989). In addition, some thyroid follicles that contain acid mucin are often grouped in the $\mathrm{C}$ cell area of the gland of humans, which are lined by abundant $\mathrm{C}$ cells (Harach, 1991). However, in goats the epithelial lining of the UB follicles was highly variable from simple squamous to columnar with or without cilia which may be stratified. Light or clear cells were seen among epithelial lining. The lumen of UBFs was filled with nucleated, non-nucleated and colloid debris which was PAS-positive (Roy et al., 1978; Harach, 1988,1991).

The follicular cells of present study were cubical or flattened in shape that possessing flat to rounded nuclei. They showed various cytoplasmic immunoreactivities against anti-calcitonin rabbit immune serum. Their cytoplasm was characterized by the presence of numerous fine electron dense membrane-bound granules measuring 150-200 nm in diameter, which distributed throughout the cytoplasm or located near the basal or vascular pole of the cell. Notably, the differentiating UBFs, UB cysts and associating SCNs exhibited various immunoreactivities against anti-calcitonin immune serum.

The solid cell nests of present investigation appeared as cystic and/or solid (squamoid) structures that mainly displaying three cell types, namely; follicular cells and polygonal or oval cells (main cells) admixed with clear or calcitonin immunoreactive cells (neuroendocrine and $C$ cells). The main cells were immunoreactive for simple and stratified epithelial-type cytokeratins, p63, and galectin-3 (Cameselle-Teijeiro et al. (2005). However, the clear cells were positive for simple-type cytokeratins, calcitonin, chromogranin and synaptophysin (CameselleTeijeiro et al., 2005). In bull, few follicular cells of UBBRs in the thyroid gland are reactive for calcitonin gene-related peptide (Harmon and Kelley, 2001). These structures represented proliferation of a mixed population of undifferentiated cells, C-cells, and thyroid follicular 
epithelial cells, presumably derived from the thyroid UB bodies (Harmon and Kelley, 2001).

The so-called mixed follicles, structures lined by epidermoid cells and follicular epithelium, are often found as an additional component of the UBBRs of present study and this finding is in line with Janzer et al. (1979), Harach (1988) and Patey et al. (1996). The mixed UBFs of present study were lined on the one side by a multi-layered cubical to squamous epithelium (epidermoid-like cells), on the other side by normal single-layered cubic follicular epithelium. These follicles might contained a peculiar intraluminal granular colloid-like material (Janzer et al., 1979; Harach, 1988) or acidic mucins (Cameselle-Teijeiro et al., 1994).

The present investigation of ultimobranchial tissue, revealed the presence of several calcitonin immunopositive aposomes at various stages of apocrine activity on the luminal surface of UB follicular cells. In this respect, apical cytoplasmic protrusions, at various phases of detachments from the apical cytoplasm of UB follicular cells, are clearly demonstrated alongside with the ordinary exocytosis. Such finding confirmed our previous hypothetical theory concerning the coexistence of both apocrine and merocrine activity in the thyroid gland of onehumped camel (Sayed et al., 1998; Atoji et al., 1999). A similar mode of secretion has been postulated in the thyroid glands of goat (Roy et al., 1978), donkey (Sayed et al., 2005b) and buffalo (Sayed et al., 2005a). However, no apocrine secretion of follicular cells has been reported in the thyroid glands of other mammalian species studied so far (Fujita, 1975).

In the present investigation of UBB vestiges, the follicular UB cells showed relatively more or less developed apical microvillus border. De Groot and Stanbury (1975) referred these microvilli as to serve for increasing the cell secretory surface. In addition, the microvilli might move in and out of the colloid along the apical border of follicular cells (Banks, 1981), or it responsible for reabsorption of colloid by pinocytosis (Fujita, 1975). Therefore, the presence of a microvillus border might closely associate with the functional activity of UB tissue.

In the present SEM investigation of UBFs and UB cysts a single cilium was usually protruded from the apical surface of follicular cells in the thyroid gland. A similar observation has been reported in the thyroid gland of some animals including dogs (Ghadially, 1988), Donkeys (Sayed et al., 2005b), camels (Sayed et al., 1998; Atoji et al., 1999) and chickens (Ghadially, 1988). In human, one to four cilia are protruding 
from the apical surface of each follicular cell (Gould et al., 1981). The significance of such cilia remain unclear, however, it have been postulated that it may exerts a chemoreceptor or mechanoreceptor function (Ghadially, 1988).

The most striking finding revealed in this investigation, during the inspection of calcitonin cells in the thyroid gland of buffalo was the concentration of this cellular type in a defined nodular area, near the capsule or alongside the septa, as well as partially embedded in thyroid tissue. In rats, C cells are more evenly distributed, but the caudal and cephalic regions of thyroid lobes contained smaller amount and they are never seen at the poles and isthmus (Monsour et al., 1985; Martin-Lacave et al., 1992). In pigs, the $C$ cells are more numerous in the deep middle region than in the cranial and caudal regions (Tsuchiya et al., 1984). A similar observation was revealed concerning the C-cells distribution pattern in dog, cat, guinea pig and mouse (Tsuchiya et al., 1984). In rhesus monkey Macaca mulatta, the $\mathrm{C}$ cells are mainly located in the central region of thyroid (Das and Das, 1978). In sheep, the C cells are more concentrated in the deep central region of thyroid lobes, decreased gradually toward periphery and they are never seen either in the isthmus or the poles of the thyroid (Okada et al., 1995). In house shrew (Suncus murinus), the $\mathrm{C}$ cells are distributed unevenly which, totally lacking from the peripheral, cranial, caudal and isthmus region (Srivastav and Swarup, 1982). In marmosets (Callithrix jacchus), the C- cells are concentrated in the middle third of thyroid (Maile and Merker, 1996). In one-humped camel, the C- cells are mainly localizeded in the UB tissue, near parathyroid (Mubarak and Sayed, 2005). In man, the C-cells are mostly located in the upper and middle parts of the lateral lobe, a few in the upper and lower poles or isthmus (Biddinger and Ray, 1993).

\section{Possible significance and functional roles of UBBRs and associating C-cells in mammalian thyroid}

The UBBRs contributes to the embryological development of the thyroid (Apel et al., 1994), and are believed to be involved in the development of C-cells (Patey et al., 1996). SCNs and mixed thyroid follicles, constituents of UBBRs, are considered as normal components of the thyroid gland in mammals (Pianzola et al., 1992; Kameda, 1995; Patey et al., 1996) and they share with C-cells a common origin in the UBB (Pianzola et al., 1992). It is postulated that the UBB contributes both C-cells and follicular cells to the thyroid in man (Williams et al., 1989; Conde et al., 1992). The presence of thyroglobulin-positive cells within solid clusters (Kamada, 1977; Harach, 1985), together with the 
existence of calcitonin positive follicular cells (present study) connected to SCNs, suggest that SCNs may also be a probable source of C-cells and follicular epithelium as occurs with the UB tissue in the thyroid gland of some mammals. Calcitonin produced by C-cells, in this setting, probably serves as an important regulator of fetal ossification and may protect against hypercalcemia during the prenatal period when there is high calcium absorption (DeLellis, 1981). Additional substances produced by C-cells include somatostatin, bombesin, substance $\mathrm{P}$, gastrin-releasing peptide, histaminase, chromogranin and neuron-specific enolase (Santa et al., 1988). This would seem to establish thyroid C-cells as members of the diffuse neuroendocrine system. In addition, these cells exhibit the characteristics of amine precursor uptake and decarboxylation (APUD) cells such as argyrophilia and cytoplasmic electron dense-cored vesicles (Norris, 1985).

Acknowledgments: Calcitonin immunostaining of present research work was carried out at the Laboratory of Veterinary Anatomy, Faculty of Applied Biological Sciences, Gifu University-Japan. Fig. 8 was prepared at the Department of Human morphology, Graduate School of Medicine and Dentistry, Okayama University-Japan.

\section{REFERENCES}

Apel, RL.; Asa, SL.; Chalvardjian, A. and LiVolsi, VA. (1994): Intrathyroidal lymphoepithelial cysts of probable branchial origin. Hum. Pathol. 25(11): 1238-42.

Atoji, Y.; Yamamoto, Y.; Suzuki, Y. and Sayed, R. (1999): Ultrastructure of the thyroid gland of the one-humped camel (Camelus dromedarius). Anat. Histol. Embyol. 28: 23-26

Banks, WJ. (1981): Applied Veterinary Histology. $1^{\text {st }}$ ed., Williams and Wilkins. Baltimore.

Biddinger, PW. and Ray, M. (1993): Distribution of C-cells in the normal and diseased thyroid gland. Pathology Annual 28: 205-229.

Calvert, $R$. (1972): Electron microscopic observations on the contribution of the ultimobranchial bodies to the thyroid histogenesis in the rat. Am. J. Anat. 133: 269-290.

Calvert, R. (1975): Structure of rat ultimobranchial bodies after birth. Anat. Rec. 181(3): 561-79.

Cameselle-Teijeiro, J.; Abdulkader, I.; Soares, P.; Alfonsín-Barreiro, N.; Moldes-Boullosa, J. and Sobrinho-Simões, M. (2005): Cystic tumor of the atrioventricular node of the heart appears to be the 
heart equivalent of the solid cell nests (ultimobranchial rests) of the thyroid. Am. J. Clin. Pathol. 123(3): 369-75.

Cameselle-Teijeiro, J.; Varela-Durán, J.; Sambade, C.; Villanueva, JP.; Varela-Núñez, R. and Sobrinho-Simoes, M. (1994): Solid cell nests of the thyroid: light microscopy and immunohistochemical profile. Hum. Pathol. 25(7): 684-93.

Conde, E.; Moreno, AM.; Martin-Lacave, I.; Fernandez, A. and Galera,

H. (1992): Immunocytochemical study of the ultimobranchial tubule in Wistar rats. Anat. Histol. Embryol. 21(1): 94-100.

Das, VK. and Das, S. (1978): Distribution of calcitonin cells in the thyroid glands of normal adult rhesus monkey (Macaca mulatta). Experientia 34: 541-542.

De Groot, L. and Stanbury, J. (1975): The thyroid and its diseases. $4^{\text {th }}$ ed., John Wiley and Sons. New York.

Delabie, J.; De Wolf Peeters, C.; Cappelle, L.; Van Damme, B. and Desmet, V. (1991): Branchial cleftlike cysts of the thyroid. Am. J. Surg. Pathol. 14: 1165-1167.

DeLellis, RA. and Wolfe, HJ. (1981): The pathobiology of the human calcitonin (C)-cell: A review. Pathol. Annu. 61: 25-52

Fujita, H. (1975): Fine structure of the thyroid gland. Int. Rev. Cytol. 40: 197-280.

Ghadially, FN. (1988): Basement membrane and basal lamina. In: Ultrastructural pathology of the cell and matrix. Butterworths, London, p 1054-1067.

Gould, VE.; Johannessen, JV. and Sobrinho-Simoes, M. (1981): The thyroid gland part 2. In: Electron microscopy in human medicine, Johonessen, ed., Vol. 10 Endocrine Organs, New york

Harach, HR. (1985): Solid cell nests of the thyroid. An anatomical survey and immunohistochemical study for the presence of thyroglobulin. Acta. Anat. (Basel). 122(4): 249-53.

Harach, HR. (1988): Solid cell nests of the thyroid. J. Pathol. 155(3): 191-200.

Harach, HR. (1991): Thyroglobulin in human thyroid follicles with acid mucin. J. Pathol. 164(3): 261-3.

Harmon, BG. and Kelley, LC. (2001): Immunohistochemistry of ultimobranchial thyroid carcinomas in seven slaughtered cows and one bull. J. Vet. Diagn. Invest. 13(2):101-5.

Janzer, RC.; Weber, E. and Hedinger, C. (1979): The relation between solid cell nests and $\mathrm{C}$ cells of the thyroid gland: an 
immunohistochemical and morphometric investigation. Cell Tissue Res. 19; 197(2): 295-312.

Kakudo, K.; Kitamura, H.; Miyauchi, A. and Takai, S. (1977): Squamous metaplasia of human thyroid gland: an electron microscopic study of solid cell nest. Med. J. Osaka Univ. 28: 33-38.

Kameda, Y. (1977): Electron microscopical and immunohistochemical study on parafollicular cell complex with reference to parafollicular cell as a paraneuron. Arch. Histol. Jpn. Suppl, 40: 133-45.

Kameda, Y. (1982): The cysts in C cell complexes of dog thyroids studied by immunoperoxidase staining and autoradiography. Arch. Histol. Jpn. 45(5): 437-48.

Kameda Y (1995): Co-expression of vimentin and 19S-thyroglobulin in follicular cells located in the C-cell complex of dog thyroid gland. J. Histochem. Cytochem. 43:1097-1106.

Kameda, Y.; Hirota, C. and Murakami, M. (1993): Immunoelectronmicroscopic localization of enkephalin in the secretory granules of $\mathrm{C}$ cells in the chicken ultimobranchial glands. Cell. Tissue. Res. 274: 257-265.

Kameda, Y. and Ikeda, A. (1980): Immunohistochemical study of the Ccell complex of dog thyroid glands with reference to the reactions of calcitonin, C-thyroglobulin and 19S thyroglobulin. Cell. Tissue. Res. 208 (3): 405-15.

Kameda, Y.; Nishimaki, T.; Chisaka, O.; Iseki, S. and Sucov, HM. (2007): Expression of the epithelial marker E-cadherin by thyroid $\mathrm{C}$ cells and their precursors during murine development. J. Histochem. Cytochem. 55(10):1075-88.

Karnovsky, MJ. (1965): A formaldehyde-glutaraldehyde fixative of high osmolality for use in electron microscopy. J. Cell. Biol. 27: 137 A - 138 A

LeDourain, N.; Fontaine, J. and LeLievre, C. (1974): New studies on the neural crest origin of the avian ultimobranchial glandular cellsinterspecific combinations and cytochemical characterization of $\mathrm{C}$ cells based on the uptake of biogenic amine precursors. Histochem. 38: 297-305

Ljungberg, O. and Nilsson, PO. (1985): Hyperplastic and neoplastic changes in ultimobranchial remnants and in parafollicular (C) cells in bulls: a histologic and immunohistochemical study. Vet. Pathol. 22(2): 95-103. 
Maile, S. and Merker, H-J. (1996): C-cells of marmosets (Callithrix jacchus). Ann. Anat. 178: 159-167.

Martin, V.; Martin, L.; Viennet, G.; Hergel, M.; Carbillet, JP. and Fellmann, D. (2000): Ultrastructural features of "solid cell nest" of the human thyroid gland: a study of 8 cases. Ultrastruct Pathol. 24(1): 1-8.

Martin-Lacave, I.; Conde, E.; Montero, C. and Galera-Davidson, H. (1992): Quantitative changes in the frequency and distribution of the C-cell population in the rat thyroid gland with age. Cell Tissue. Res. 270: 73-77

Mérida-Velasco, JA.; García-García, JD.; Espín-Ferra, J. and Linares, $J$. (1989): Origin of the ultimobranchial body and its colonizing cells in human embryos. Acta. Anat. (Basel). 136(4):325-30.

Michal, M.; Mukensnabl, P. and Kazakov, DV. (2006): Branchial-like cysts of the thyroid associated with solid cell nests. Pathol. Int. 56: $150-153$

Mizukami, Y.; Nonomura, A.; Michigishi, T.; Noguchi, M.; Hashimoto, T.; Nakamura, S. and Ishizaki, T. (1994): Solid cell nests of the thyroid. A histologic and immunohistochemical study. Am. J. Clin. Pathol. 101: 186-91.

Monsour, PA.; Kruger, BJ. and Barnes, A. (1985): Calcitonin cell population and distribution in the thyroid gland of the rat. $\mathrm{J}$. Morphol. 186: 271-278

Mubarak, W. and Sayed, R. (2005): Ultramicroscopical study on thyrocalcitonin cells in the camel (Camelus dromedarius). Anat. Histol. Embryol., Suppl. 1, 34:35

Norris, DO. (1985): Vertebrate Endocrinology. Philadelphia: Lea and Febiger, p162-201, 321.

Okada, H.; Shigeta, Y. and Un-No, Y. (1995): C- cell distribution in ovine thyroid gland. Anat. Histol. Embyol. 24: 281-284.

Ozaki, O.; Ito, K.; Sugino, K.; Yasuda, K.; Yamashita, T.; Toshima, K. and Hosoda, Y. (1991): Solid cell nests of the thyroid gland. Virchows Arch. A. Pathol. Anat. Histopathol. 418: 201-5.

Park, J-Y.; Kim, GY. and Suh, Y-L. (2004): Intrathyroidal branchial cleftlike cyst with heterotopic salivary gland-type tissue. Pediatr. Dev. Pathol. 7: 262-267.

Patey, M,; Flament, JB.; Caron, J.; Delisle, MJ.; Delemer, B. and Pluot, M. (1996): Bilateral Thyroid and Ultimobranchial Medullary Carcinoma. Endocrionl. Pathol. 7: 349-354. 
Pearse, AGE. and Polak, JM. (1971): Cytochemical evidence for the neural crest origin of mammalian ultimobranchial $\mathrm{C}$ cells. Histochem. 27: 96-102.

Pianzola, HM.; Ottino, A. and Castelletto, RH. (1992): Solid cell nests of the thyroid gland. Optic and immunohistochemical study at autopsies. Acta. Anat. (Basel). 143(1): 79-83.

Polak, JM.; Pearse, AGE. and LeLievre, C. et al. (1974): Immunocytochemical confirmation of the neural crest origin of avian calcitonin-producing cells. Histochem. 40: 209-214

Roediger, WE.; Kalk, F.; Spitz, L. and Schmaman, A. (1977): Congenital thyroid cyst of ultimobranchial gland origin. J. Pediatr. Surg. 12: 575-6.

Roy, KS.; Saigal, RP.; Nanda, BS. and Nagpal, SK. (1978): Gross, histomorphological and histochemical changes in thyroid gland of goat with age. II. Occurrence of ultimobranchial follicles. Anat. Anz. 143: 72-85.

Roy, KS. and Yadava, RCP. (1975): Histological and certain histochemical observations on the light cells of the thyroid gland in the Indian buffalo. Indain. J. Animal. Sci. 43: 706-710.

Sadler, TW. (1990): Langman's Medical Embryology. Baltimore: Williams \& Wilkins. 307-309.

Santa, G.; Carcangiu, ML. and Rosai, J. (1988): The biochemical and immunohistochemical profile of thyroid neoplasms. Pathol. Annu. 23: 129-157.

Sayed, R.; Aly, KH. and Mubarak, W. (2005a): Surface ultrastructure of ultimobranchial remnants in the thyroid gland of buffalo (Bos bubalis). Anat. Histol. Embryol. Suppl., 1, 34:45

Sayed, R.; Atoji, Y. and Kelany, AM. (1998): Ultrastructural studies on the thyroid gland of one-humped camel. XXII EAVA Congress, Naples, Italy, July 26-30.

Sayed, R.; Saleh, AM. and Mubarak, W. (2005b): Surface ultrastructure of ultimobranchial epithelium in the thyroid gland of donkey (Equus asinus). Anat. Histol. Embryol. Suppl., 1, 34:45

Srivastav, AK. and Swarup, K. (1982): Morphology and distribution of calcitonin cells in the house shrew, Suncus murinus. Arch. Anat. Microsc. Morphol. Exp. 71: 207-212.

Sugiyama, S. (1971): The embryology of the human thyroid gland including ultimobranchial body and others related. Ergeb. Anat. Entwicklungsgesch 44: 1-111. 
Tsuchiya, T.; Shiomura, Y.; Suzuki, K.; Nagai, H. and Tamate, H. (1984): Immunocytochemical study on the C cells in pig thyroid glands. Acta. Anat. 120: 138-141.

Wetzel, BK. and Wollman, SH. (1969): Fine structure of a second kind of thyroid follicle in the $\mathrm{C} 3 \mathrm{H}$ mouse. Endocrinol. 84: 563-578.

Williams, ED.; Toyn, CE. and Harach, HR. (1989): The ultimobranchial gland and congenital thyroid abnormalities in man. J. Pathol. 159: 135-41.

Zelander, T. and Kirkeby, S. (1977): Fine structure of the ultimobranchial cysts in the thyroid of the adult guinea pig. Cell. Tissue. Res. 30; 183: 343-51. 